\title{
Model performance of tree height-diameter relationships in the central Congo Basin
}

\author{
Elizabeth Kearsley ${ }^{1,2,3} \cdot$ Pieter CJ Moonen $^{4} \cdot$ Koen Hufkens $^{2,5} \cdot$ Sebastian Doetterl $^{2,6}$ • \\ Janvier Lisingo ${ }^{7}$. Faustin Boyemba Bosela ${ }^{7}$ - Pascal Boeckx ${ }^{2}$ - Hans Beeckman ${ }^{3}$. \\ Hans Verbeeck ${ }^{1}$
}

Received: 13 June 2016 / Accepted: 14 December 2016 / Published online: 6 February 2017

(C) INRA and Springer-Verlag France 2017

\begin{abstract}
- Key message Tree heights in the central Congo Basin are overestimated using best-available height-diameter models. These errors are propagated into the estimation of aboveground biomass and canopy height, causing significant bias when used for calibration of remote sensing products in this region.
\end{abstract}

Handling Editor: Gilbert Aussenac
Contribution of the co-authors
HV and PB developed the research project. EK, PM, KH, JL, and FBB
collected data. EK analyzed the data. EK, PM, KH, SD, and HV
interpreted the results and implications. HV, PB, and HB supervised the
research. EK wrote the paper. All authors commented on the manuscript
during the final stages.

Electronic supplementary material The online version of this article (doi:10.1007/s13595-016-0611-0) contains supplementary material, which is available to authorized users.

Elizabeth Kearsley

elizabeth.kearsley@ugent.be

Pieter CJ Moonen

pieter.Moonen@ees.kuleuven.be

Koen Hufkens

khufkens@fas.harvard.edu

Sebastian Doetterl

sebastian.doetterl@geo.uni-augsburg.de

Janvier Lisingo

lisingo2005@yahoo.fr

Faustin Boyemba Bosela

faustinboyemba@yahoo.fr

Pascal Boeckx

pascal.boeckx@ugent.be
- Context Tree height-diameter models are important components of estimating aboveground biomass (AGB) and calibrating remote sensing products in tropical forests.

- Aims For a data-poor area of the central Congo Basin, we quantified height-diameter model performance of local, regional and pan-tropical models for their use in estimating AGB and canopy height.

- Methods At three old-growth forest sites, we assessed the bias introduced in height estimation by regional and pantropical height-diameter models. We developed an optimal local model with site-level randomizations accounted for by using a mixed-effects modeling approach. We quantified the error propagation of modeled heights for estimating AGB and canopy height.

- Results Regional and pan-tropical height-diameter models produced a significant overestimation in tree height, propagating into significant overestimations of AGB and Lorey's height. The pan-tropical model accounting for climatic drivers performed better than the regional models. We present a local height-diameter model which produced nonsignificant errors for AGB and canopy height estimations at our study area.

- Conclusion The application of general models at our study area introduced bias in tree height estimations and the derived stand-level variables. Improved delimitation of regions in tropical Africa with similar forest structure is needed to produce models fit for calibrating remote sensing products.

Keywords Allometry · Error propagation · Biomass · Lorey's height $\cdot$ Size-density distributions $\cdot$ Tropical forest

\section{Introduction}

Tree height-diameter models are useful tools aiding in improving the accuracy of tropical forest aboveground biomass (AGB) estimations. Allometric models to convert forest 
inventory data into an estimate of AGB perform better when tree height is included (Feldpausch et al. 2012; Popkin 2015). Furthermore, many remote sensing products measure canopy height rather than AGB and are dependent on tree height data for their calibration (Asner and Mascaro 2014; Lei and Siqueira 2014; Saatchi et al. 2011; Schlund et al. 2015; Wang et al. 2016). However, specifically in tropical forests, data availability on tree height is impeded by the difficulty of its measurement in closed-canopy forests (Larjavaara and Muller-Landau 2013), including the related time- and costconsuming character of the measurement. This difficulty in data acquisition has led to tree height often being overlooked in carbon-accounting programs (Hunter et al. 2013; Larjavaara and Muller-Landau 2013), resulting in possible increased bias. Moreover, an important fraction of carbon storage variability in tropical forests related to forest structure is overlooked. Nevertheless, this data acquisition issue can be overcome through the use of height-diameter models, in spite of the introduced model error (Chave et al. 2014; Feldpausch et al. 2012). However, accounting for environmental and spatial variability within these models is an important aspect.

Height-diameter relationships are site-dependent (Curtis 1967; Huang et al. 2000; Saunders and Wagner 2008; Trorey 1932) and can depend on a multitude of local factors including soil properties (Aiba and Kitayama 1999; Heineman et al. 2011; Urban et al. 2013), light environment and neighboring effects (Henry and Aarssen 1999; Holbrook and Putz 1989; Poorter et al. 2003), and stand development (Curtis 1967; Kohyama et al. 1990; Sterck and Bongers 1998). Height-diameter models are therefore often specific to locations, stand types, and site fertility (e.g., Huang et al. 2000; Stout and Shumway 1982). The allometry of a tree is also affected by environmental factors including climate conditions and altitude (Banin et al. 2012; Feldpausch et al. 2011;

Hans Beeckman

hans.beeckman@africamuseum.be

Hans Verbeeck

hans.verbeeck@ugent.be

1 Department of Applied Ecology and Environmental Biology, Ghent University, Ghent, Belgium

2 Department of Applied Analytical and Physical Chemistry, Ghent University, Ghent, Belgium

3 Service of Wood Biology, Royal Museum for Central Africa, Tervuren, Belgium

4 Department of Earth and Environmental Sciences, KU Leuven, Leuven, Belgium

5 Department of Organismic and Evolutionary Biology, Harvard University, Cambridge, USA

6 Institute of Geography, Augsburg University, Augsburg, Germany

7 Faculté des Sciences, Université de Kisangani, Kisangani, Democratic Republic of the Congo
Hulshof et al. 2015; Lines et al. 2012; Wang et al. 2006). Based on pan-tropical height-diameter analyses, Banin et al. (2012) and Feldpausch et al. (2011) show that region-specific models significantly reduce the bias related to the variation in tree height for different tropical regions. More recently, Chave et al. (2014) suggest that this regional variability can be explained by bioclimatic factors, and they therefore propose a single pan-tropical height-diameter model with a linear dependency on a bioclimatic stress variable. These models show large potential to serve as calibration or validation tools for remote sensing products. However, keeping in mind that numerous other factors can drive height-diameter variability, the validity of using these models in different tropical forest regions needs to be quantified.

In this regard, tropical Africa and more specifically the Congo Basin have a particular high need for allometric model validation. These regions are however prone to data limitations due to a lack of resources for scientific research, limited logistical support, poor infrastructure, and periodic political instability (Verbeeck et al. 2011). These data limitation issues, particularly poor spatial coverage, restrict different aspects of monitoring, reporting, and verification (MRV) protocols of carbon storage, essential within carbon-accounting programs. With respect to spatial variability, significant intra-continental differences of AGB and forest structure are reported for tropical Africa (Lewis et al. 2013), although the central Congo Basin is underrepresented in the study. In the central Congo Basin, a site-specific study (Kearsley et al. 2013) has identified lower asymptotic tree heights compared to the outer regions of the Congo Basin (Banin et al. 2012; Feldpausch et al. 2011). With this study, we enlarge the spatial scale of the former study (Kearsley et al. 2013) to identify if tree heights are consistently lower in this region. Furthermore, we aim to quantify height-diameter model performance of local, regional, and pan-tropical models for their use in estimating standlevel variables, specifically AGB and canopy height. This evaluation of model performance, specifically in this datapoor region, is critical for calibration of remote sensing data.

\section{Material and methods}

\subsection{Study area and data collection}

This study was carried out at three lowland tropical forest study areas (without signs of recent human interventions) in the region of Kisangani, Democratic Republic of the Congo (DRC), namely, Yangambi, Yoko, and Yambela (Fig. 1, Table 1). Vegetation in this region is characterized by moist semi-deciduous rainforest, with fragments of moist evergreen rainforest, transition forest, agricultural land, fallow land, and swamp forest (Gilson et al. 1956). All sites are within approximately $100 \mathrm{~km}$ distance from each other, and a similar climate 


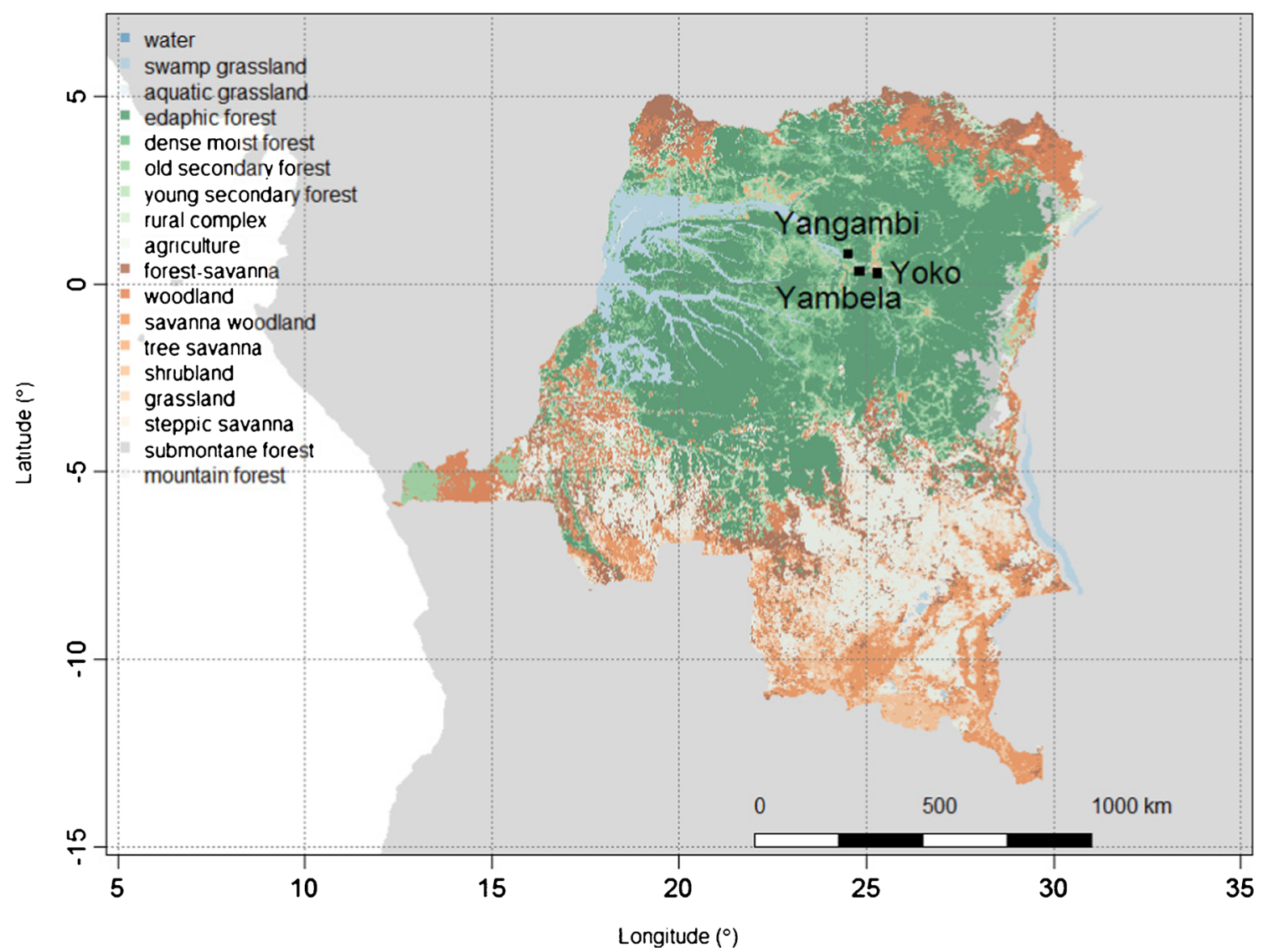

Fig. 1 Location of the three study sites Yangambi, Yoko, and Yambela on a land cover map of DRC (Verhegghen et al. 2012)

is assumed. As measured in the Yangambi reserve, the region receives an annual precipitation of $1840 \pm 206 \mathrm{~mm}(1980$ 2012) with an average dry season length of $3.3 \pm 1.3$ months

Table 1 Site characteristics

\begin{tabular}{llll}
\hline & Yangambi & Yoko & Yambela \\
\hline Stand characteristics & & & \\
$\quad$ Stem density $\left(\mathrm{ha}^{-1}\right)$ & $419 \pm 89 \mathrm{a}$ & $469 \pm 35 \mathrm{a}$ & $467 \pm 58 \mathrm{a}$ \\
Basal area $\left(\mathrm{m}^{2} \mathrm{ha}^{-1}\right)$ & $32 \pm 3 \mathrm{a}$ & $34 \pm 3 \mathrm{a}$ & $31 \pm 5 \mathrm{a}$ \\
Wood density $\left(\mathrm{g} \mathrm{cm}^{-3}\right)$ & $0.63 \pm 0.02 \mathrm{a}$ & $0.64 \pm 0.02 \mathrm{a}$ & $0.63 \pm 0.04 \mathrm{a}$ \\
Max DBH $(\mathrm{cm})$ & $127 \pm 17 \mathrm{a}$ & $114 \pm 18 \mathrm{a}$ & $99 \pm 27 \mathrm{a}$ \\
Mean DBH $(\mathrm{cm})$ & $26 \pm 2 \mathrm{a}$ & $24 \pm 1 \mathrm{a}$ & $24 \pm 3 \mathrm{a}$ \\
Coordinates & & & \\
Latitude & 0.7995 & 0.2918 & 0.3493 \\
Longitude & 24.5077 & 25.3113 & 24.8217 \\
Altitude (masl) & $479 \pm 13$ & $471 \pm 5$ & $457 \pm 24$ \\
Plot size (ha) & 1 & $0.25-1$ & $0.25(0.0625)$ \\
Number of plots & 5 & 5 & 11
\end{tabular}

Plot averages and standard deviations are provided for the different sites. Plot-level mean wood density is weighted by basal area. For each parameter, significance from Tukey's honestly significant difference test is provided between brackets comparing the three sites. Values within a row not sharing a common letter differ significantly with monthly precipitation lower than $100 \mathrm{~mm}$, during December-February. Temperatures are high and constant throughout the year with a minimum of $24.2 \pm 0.4{ }^{\circ} \mathrm{C}$ in July and a maximum of $25.5 \pm 0.6^{\circ} \mathrm{C}$ in March. The geology of the region consists of unconsolidated aeolian sedimentary sandy material of Pleistocene age, giving way to Xanthic Ferralsols (sensu World reference base, WRB for soil resources 2014; Van Engelen et al. 2006). In the vicinity of the Congo River and tributaries, the geology is more complex and consists of both alluvial/lacustrine material as well as displaced material from the surroundings.

The first study area was located at the UNESCO Man and Biosphere reserve in Yangambi $\left(\mathrm{N}_{0} 0^{\circ} 48^{\prime}\right.$; E24 $\left.{ }^{\circ} 29^{\prime}\right)$ where permanent sampling plots were inventoried in 2012 (Kearsley et al. 2013). Five plots of 1 ha were selected in mixed semi-deciduous old-growth forest, all situated within a $5-\mathrm{km}$ radius from each other. All trees with a diameter at breast height (DBH) $\geq 10 \mathrm{~cm}$ were measured, mapped, and identified to species level. The most abundant species were Scorodophloeus zenkeri Harms, Staudtia kamerunensis Warb., Petersianthus macrocarpus (P.Beauv.) Liben, Panda oleosa Pierre, and Anonidium mannii (Oliv.) Engl. \& Diels. Based on this inventory, a subset of trees were selected for height measurement by stratified random sampling. Two levels of strata were formed, namely, species identity and 
DBH classes of 10-20, 20-30, 30-50, and $\geq 50 \mathrm{~cm}$. Next, two individuals were randomly selected with each strata when possible (excluding damaged or leaning $(>10 \%)$ trees). In total, 487 individual trees were measured for height covering 98 species (14 individuals only identified to genus level). The second study area was located at the Yoko forest reserve $\left(\mathrm{N} 00^{\circ} 17^{\prime}\right.$; E25 $\left.{ }^{\circ} 18^{\prime}\right)$ where five 1-ha plots were inventoried, all localized within a $1.5-\mathrm{km}$ radius. In these plots, all trees with $\mathrm{DBH} \geq 10 \mathrm{~cm}$ were measured for $\mathrm{DBH}$ and mapped and species were determined. S. zenkeri, Cynometra hankei Harms, Polyalthia suaveolens Engl. \& Diels, and Prioria oxyphylla (Harms) Breteler were most abundant. Tree height was measured for all trees with $\mathrm{DBH} \geq 10 \mathrm{~cm}$ in four smaller plots of 0.25 ha, although excluding damaged or leaning $(>10 \%)$ trees. In total, 436 individual trees were measured for height covering 70 species ( 7 individuals only identified to genus level). The third study area was located in Yambela $\left(\mathrm{N} 00^{\circ} 21^{\prime} ; \mathrm{E} 24^{\circ} 49^{\prime}\right)$. At Yambela, data collection was part of a different project with a different inventory approach. Here, a nested sampling was used. Trees with $\mathrm{DBH} \geq 30 \mathrm{~cm}$ were measured in 110.25 -ha plots, and smaller trees with DBH $10-30 \mathrm{~cm}$ were measured within $25 \times 25$-m subplots. All plots were located within a $5-\mathrm{km}$ radius. Trees were identified to species level, presenting an abundance of $S$. zenkeri, Brachystegia laurentii (De Wild.) Hoyle, A. mannii, Gilbertiodendron dewevrei (De Wild.) J.Leonard, and P. macrocarpus. Both B. laurentii and G. dewevrei are gregarious species, but their gregarious nature was not expressed in these mixed forest plots. Based on the forest inventory, a stratified random sampling was used to select trees for height measurement, with two strata based on DBH class: 10-50 and $\geq 50 \mathrm{~cm}$. Twenty-five percent of the trees were randomly sampled in the smallest DBH class and 50\% in the largest class. Again, trees that were damaged or leaning $(>10 \%)$ were excluded. One hundred forty-three individual trees were measured for height covering 53 species ( 8 individuals only identified to genus level).

At all study areas, DBH measurements were made following the RAINFOR protocol (Phillips et al. 2010). Accordingly, buttressed trees, although a rarity in the region, and stilt-rooted trees were measured $50 \mathrm{~cm}$ above the highest root, where the trunk shape was cylindrical. When a deformity was present at breast height, the diameter was measured $2 \mathrm{~cm}$ lower. Tree heights at all three study areas were measured using a Nikon Laser Rangefinder Forestry Pro hypsometer. The top of the tree was determined from different view angles, and multiple measurements were made to account for over- or underestimation. When the top of an individual was not visible, a different individual using the same selection criteria was selected. This was however only necessary for a few instances, and attention was paid not to introduce a selection bias. Two aspects in this study should be noted: (1) Height measurements at the three study areas were made within the context of different projects. Two measurement teams were available, one for Yambela, and one for Yangambi and Yoko. Nevertheless, all observers used the same protocol for height observations. (2) Height measurements in themselves are prone to measurement errors (Larjavaara and MullerLandau 2013) which, with no control available, was not accounted for in this study. Furthermore, within the range of leaning trees included in this study (nonleaning to leaning $<10 \%$ ), no distinction was made between length and height of the tree, which reflects an additional dimension of measurement error.

For the remainder of the text, the three study areas are referred to as "sites," and the investigated site dependencies of the height-diameter models represent the following characteristics. The three sites (located $\sim 100 \mathrm{~km}$ apart) are similar in climate, with soils representing a sample of a larger population of possible soils in the central basin. Although the dominant soil unit (sensu World reference base, WRB for soil resources 2014) is the same for the three sites (according to Van Engelen et al. 2006), regional differences in landscape position have likely led to spatial autocorrelation of soil characteristics within a study area, as well as larger differences between study areas. Furthermore, as investigated later on, differences in forest structural characteristics and floristic composition were present even though all sites were classified as the same forest type. Moreover, although no signs of recent human activities were found at the study areas, disturbance history of the sites could differ, as investigated and discussed further on. Finally, sampling protocol and systematic differences made by different observers added a level of measurement uncertainty.

\subsection{Stand characteristics}

General stand characteristics were computed for each site at plot level, namely, stem density, basal area, mean wood density, and mean and maximum stem diameter. One-way analysis of variance was used followed by Tukey's honestly significant difference (HSD) test to compare the mean values of the stand characteristics of the three sites. The floristic composition of the plots was compared using a detrended correspondence analysis (DCA) (Hill and Gauch 1980). The analysis was performed using the VEGAN 2.0 package (Oksanen 2013) and was based on the basal area of species with DBH $\geq 30 \mathrm{~cm}$ in each plot. Furthermore, tree size-density distributions (SDD) were investigated as an indicator for successional status of the forests at the three sites. We evaluated how well the SDD were fit by a scaling function and by a negative exponential function, since a scaling relationship can indicate that competition is driving the SDD, while a negative exponential function for SDD can be related to exogenous disturbance (Coomes et al. 2003). Models were fitted by nonlinear least-squares estimations ("nls" function in "nlme" package in R software; Pinheiro et al. 2009). All SDD were determined 
using a 2-cm bin size. For model fitting, we excluded bins with stem density lower than 5 , since low stem densities (mainly in large diameter classes) increased the variance, and inclusion of these classes in least-squares regressions violated homogeneity of variance assumptions (following Coomes et al. 2003).

\subsection{Height-diameter model development}

The statistical analysis consisted of three main stages. First, a selection was made of the best model function for this region, referred to as the local model. Secondly, site-level variability was assessed by introducing site as random effect in a nonlinear mixed effects (NLME) version of the local model. Finally, the selected model was compared to regional models for central Africa, namely, Feldpausch et al. (2012) and Banin et al. (2012), and the pan-tropical model presented by Chave et al. (2014).

\subsubsection{Height-diameter model selection}

To select the optimal height-diameter model for the study region, six commonly used function forms were compared (Supplementary Table S1). All models were fitted by nonlinear least-squares estimations (Pinheiro et al. 2009) for the three study sites combined. The best model fit was selected by comparing the Akaike information criterion (AIC; Burnham and Anderson 2002) and the standard deviation of residuals (residual standard error;RSE $=\sqrt{\frac{1}{d f} \sum_{i=1}^{n}\left(Y_{i}-\hat{Y}_{i}\right)^{2}}$ ), a measure of the variation explained by the model and residuals to assess any model-specific biases (Supplementary Table S2 and Figs. S1, S2, and S3). The three-parameter exponential function provided the best statistical fit, as demonstrated by the lowest AIC and RSE values (Supplementary Table S2). Nonetheless, the difference between the best fit and the worst fit was not large. Additionally, residual analysis did not reveal large differences between the studied function forms (Supplementary Fig. S1).

\subsubsection{A local model}

The three-parameter exponential equation was selected for further analysis:

$H=a-b e^{-c D}$

In this function, $H$ is the individual tree height, $D$ is the diameter at breast height, and $a, b$, and $c$ are the estimated model parameters, which represent, respectively, the maximum asymptotic height, the difference between minimum and maximum height, and the shape of the curve (Banin et al. 2012). This model is further referred to as the local model. Fivefold crossvalidation was performed to evaluate the model by dividing the data into a training subset $(80 \%)$ and a validation subset $(20 \%)$. Estimated heights $\left(\hat{H}_{i}\right)$ were compared to measured heights $\left(H_{i}\right)$ of the validation dataset by a mean signed deviation $\left(\mathrm{MSD}=\frac{1}{n} \sum_{i=1}^{n}\left(H_{i}-\hat{H}_{i}\right)\right)$ indicating underestimation (positive sign) or overestimation (negative sign) of tree height. Paired $t$ tests between estimated and measured heights were performed to test the significance of difference between them.

\subsubsection{NLME local model}

The conditions at the three sites used for setting up the local model can have an important influence on the height-diameter relationship. Since trees within the same site are likely to be more similar in allometry than trees selected from multiple sites covering larger areas, related to stand density and site-specific characteristics, residuals were expected to be site dependent. Moreover, protocol differences between sites or potential systematic differences in height measurements related to the observer could add to this site dependency. NLME models can however account for this dependence. The local model was therefore also assessed by a NLME model, with site introduced as random effect (using nlme function in nlme package in $\mathrm{R}$ software; Pinheiro et al. 2009). We tested the random structure by keeping the fixed effects structure constant and applying different combinations of random effects to the model parameters (tested as described in Pinheiro and Bates 2000, Chapter 6). The best model fit was selected based on AIC (Burnham and Anderson 2002) and RSE. This resulted in the partial NLME version of the threeparameter exponential local model:

$H_{i j}=\left(a+\alpha_{i}\right)-\left(b+\beta_{i}\right) e^{-(c) D_{j}}+\varepsilon_{i j}$

with sites $i$ and individuals $j$. The fixed effects $a, b$, and $c$ represent the mean values of the parameters in the population of individuals. The site deviations are represented by the random effects $\alpha_{i}$ and $\beta_{i}$. The errors $\varepsilon_{i j}$ are independently distributed as $\mathrm{N}\left(0, \sigma^{2}\right)$ and independent of the random effects. Parameters were estimated using the restricted maximum likelihood (REML) method. This allows for a comparison between the NLME model and the local model by ANOVA to test the significance of including the random effects, as both models have the same fixed effects. Model evaluation was again done using a fivefold cross-validation and MSD, and paired $t$ tests were used to assess the difference in estimated and modeled heights. 


\subsubsection{Comparison with regional and pan-tropical models}

The regional height-diameter models for central Africa by Banin et al. (2012) and Feldpausch et al. (2012) were tested for our study region, respectively Eqs. 3 and 4. These models mainly differ in their spatial boundaries. The model of Banin et al. (2012) was based on data from lowland, tropical moist forest stands of all tropical Africa. Feldpausch et al. (2012) divided tropical Africa into three regions, namely, west, central, and east Africa, of which we focused on the central African relationship (Eq. 4) based on data from central and southern Cameroon and Gabon. The pan-tropical model by Chave et al. (2014) was also tested, Eq. 5, which includes a climatic variable E, a measure of environmental stress, here attained from the global grid layer provided by Chave et al. (2014).

$H=45.1-42.8 \cdot e^{-0.025 \cdot D}$

$H=50.453 \cdot\left(1-e^{-0.0471 D^{0.8120}}\right)$

$\ln (H)=0.893-E+0.760 \ln (D)-0.0340(\ln (D))^{2}$

A comparison was made between these models and our local model. Specifically, a residual analysis was performed for each model comparing actual measured heights with predicted heights by the MSD (and RMSE in Supplementary Table S3), and the significance of these differences between measured and predicted heights was tested using paired $t$ tests.

\subsection{Model performance for estimating stand-level AGB and Lorey's height}

The use of both measured and modeled heights for determining stand-level variables was assessed. Two key stand variables were tested, namely, AGB and canopy height. AGB was estimated with the pan-tropical model by Chave et al. (2014) (Eq. 6):

$\mathrm{AGB}_{\mathrm{est}}=0.0673 \times\left(\rho D^{2} H\right)^{0.976}$

accounting for wood density $(\rho)$, DBH $(D)$, and height $(H)$. Wood density was measured locally at Yangambi (Kearsley et al. 2013). For species not available in this local dataset, wood density was extracted from the global wood density database (Chave et al. 2009). For unidentified species and genera for which no wood density data was found in literature, a genus-level, family-level, or site-level average was taken. AGB was estimated using both measured $H$ values and modeled $\mathrm{H}$ values, namely, estimated heights from the local NLME model, the two regional central African (Banin et al. 2012; Feldpausch et al. 2012) and pan-tropical (Chave et al. 2014) models.
Lorey's height $\left(\mathrm{H}_{\text {Lor }}\right.$; Eq. 7$)$, a basal area (BA) weighted mean tree height, was selected to represent canopy height:

$\mathrm{H}_{\text {Lor }}=\frac{\sum_{i=1}^{N} \mathrm{BA}_{i} \mathrm{H}_{i}}{\sum_{i=1}^{N} \mathrm{BA}_{i}}$

with individuals $i$. $H_{\text {Lor }}$ was again estimated using both measured and the four modeled heights.

Next, the model performance of the four models for estimating these two stand-level variables was assessed by goodness-of-fit measures $\frac{\mathrm{AGB}_{m}-\mathrm{ABG}_{i}}{\mathrm{AGB}_{m}}$ and $\frac{\mathrm{H}_{\mathrm{Lor}, m}-\mathrm{H}_{\mathrm{Lor}, i},}{\mathrm{H}_{\mathrm{Lor}, m}}$, with $\mathrm{AGB}_{m}$ and $\mathrm{H}_{\mathrm{Lor}, \mathrm{m}}$ estimated using the measured height and $\mathrm{AGB}_{i}$ and $\mathrm{H}_{\mathrm{Lor}, i}$ estimated using the four models $i$.

\section{Results}

The residual analysis comparing measured and estimated tree heights showed that both regional models (Banin et al. 2012; Feldpausch et al. 2012) produced a significant $(p<0.001)$ overestimation for tree heights in this region (Figs. 2 and 3, Table 2). The pan-tropical model (Chave et al. 2014) however performed better with smaller residual errors, i.e., smaller overestimations of height, although still significantly different from the measured heights. At the Yambela site, this pantropical model even produced only marginally significant differences $(p=0.08)$ from the measured heights (Table 2). For both regional and pan-tropical models, the residual error was larger for trees with a larger DBH (Fig. 3; Supplementary Table S3). The local model (Table 3 ) produced significantly smaller residual errors (Table 2; Fig. 3d), although it did not perform equally well at the three sites, with an overall overestimation for Yangambi and underestimation for Yambela. Introducing site as a random effect in the local model significantly $(p=0.001)$ improved the model, with the NLME model (Table 3) having lower AIC and RSE values and the residual analysis showing no significant differences between measured and estimated heights. Site-specific deviations were reflected in the model parameters (Table 3), mainly with Yangambi showing a lower asymptotic tree height parameter "a" than the two other sites.

Error propagation from using modeled heights for the estimation of the two stand-level characteristics AGB and $\mathrm{H}_{\mathrm{Lor}}$ was found. Overestimated tree heights produced by the regional models translated into significant overestimations in both stand-level characteristics (Figs. 4 and 5), all other parameters unchanged ( $\rho, \mathrm{DBH}$, and BA). Namely, estimated heights from the regional Feldpausch et al. (2012) model translated into significant overestimations of AGB by $27 \pm 8,23 \pm 9$, and $16 \pm 9 \%$ and of $\mathrm{H}_{\text {Lor }}$ by $30 \pm 8,23 \pm 10$, and $18 \pm 11 \%$, for Yangambi, Yoko, and Yambela, respectively. Similarly, the use of the regional Banin et al. 


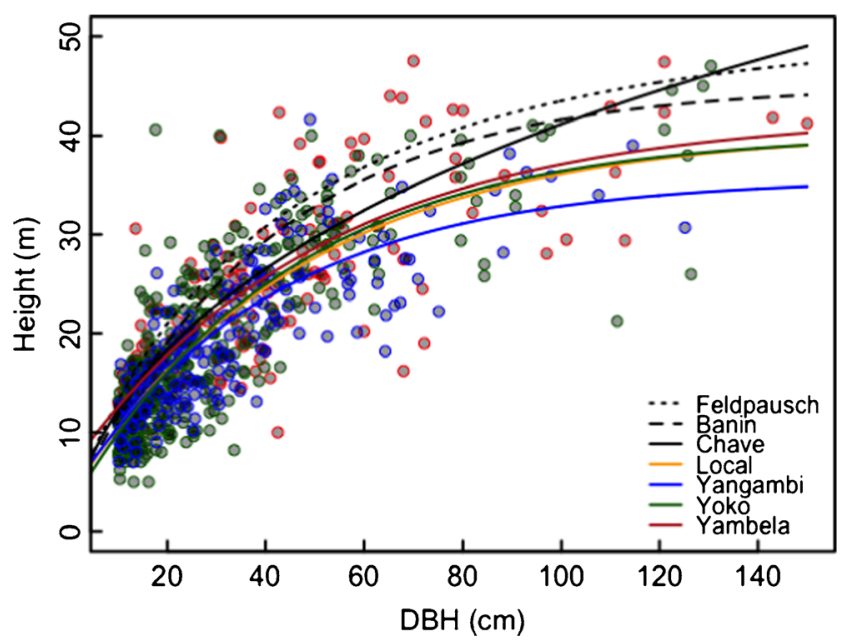

Fig. 2 Height-diameter models for the studied region, namely, the local model (orange) and the mixed effects local model with site-specific deviations for Yangambi (blue), Yoko (green), and Yambela (red). The regional models for central Africa by Feldpausch et al. (2012) (black dotted line) and Banin et al. (2012) (black dashed line) and the pantropical model by Chave et al. (2014) (full black line) are indicated

(2012) model produced overestimations in AGB by $21 \pm 8$, $17 \pm 8$, and $11 \pm 9 \%$ and of $\mathrm{H}_{\text {Lor }}$ by $23 \pm 8,17 \pm 10$, and $12 \pm 10 \%$ for Yangambi, Yoko, and Yambela. The pantropical Chave et al. (2014) model also produced significant overestimations at the Yangambi and Yoko sites by $13 \pm 10$ and $12 \pm 7 \%$ for AGB and by $14 \pm 10$ and $12 \pm 8 \%$ for $\mathrm{H}_{\mathrm{Lor}}$ At Yambela, the error was significantly smaller with an average overestimation of $6 \pm 10 \%$ for AGB and $7 \pm 12 \%$ for $\mathrm{H}_{\text {Lor }}$ At several plots in Yambela, the pan-tropical model produced underestimations (Figs. 4 and 5). The incorporation of heights estimated using the local NLME model did produce similar AGB and $\mathrm{H}_{\text {Lor }}$ estimates as the use of measured heights, with relative errors of $1 \pm 6$ and $1 \pm 7 \%$ across all sites.

Site as a random variable was thus important, even though basic forest structure variables for the three sites were highly similar, namely, plot-specific basal area, stem density, weighted wood density, and mean and maximum stem diameter (Table 1). Species composition (BA weighted) was significantly different between Yambela and the two others sites (Supplementary Fig. S4). Yoko and Yangambi did show some distinction in species composition in the DCA (Supplementary Fig. S4), although not significantly $(p=0.1)$. Differences in SDD between the sites were found, with SDD for Yoko and Yambela being best fit by the scaling function, while for Yangambi, the negative exponential function best fitted the SDD (Table 4). Accordingly, on the log-log axes, the SDD was downwardly curved for Yangambi and linear for Yoko, while on the log-linear axes the SDD was linear for Yangambi and upwardly curved for Yoko (Fig. 6). For Yambela, the shape of the curve was less clear due to fewer sampling points.
Fig. 3 Residual analysis of height estimations of the three sites Yangambi (blue), Yoko (green), and Yambela (red) of the models by Feldpausch et al. (2012) (a); Banin et al. (2012) (b); Chave et al. (2014) (c); and the local NLME model (d). DBH is presented on a logarithmic scale
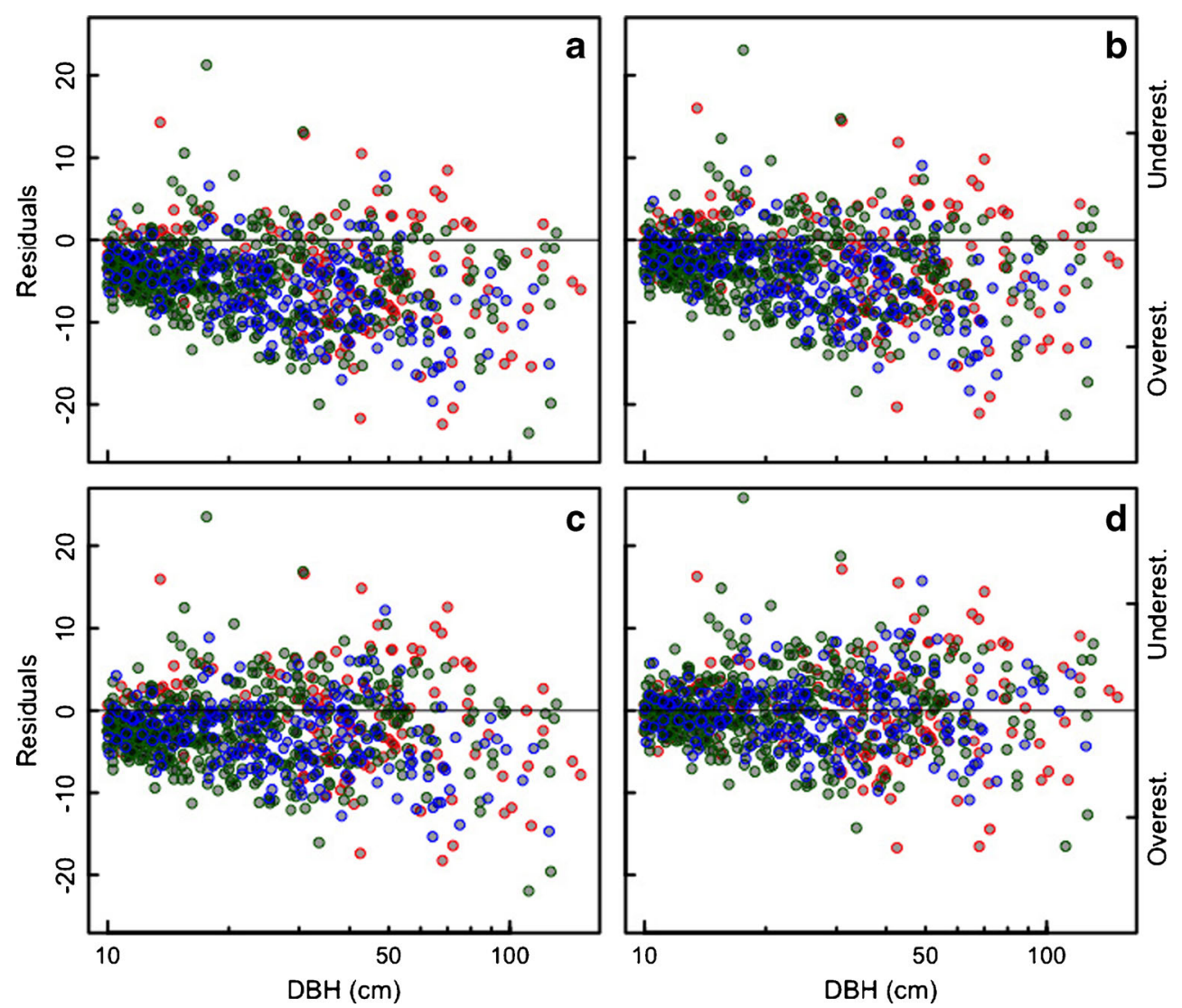
Table 2 Mean signed deviation (MSD) and $p$ values of paired $t$ test (between brackets) between measured heights and estimated heights by the local model, NLME model accounting for site-specific variation, two regional models (Feldpausch et al. 2012; Banin et al. 2012), and the pan-tropical model (Chave et al. 2014)

\begin{tabular}{llllll}
\hline & Local & NLME & Feldpausch & Banin & Chave \\
\hline Yangambi & $-1.1(0.08)$ & $-0.2(0.78)$ & $-6.1(<0.001)$ & $-4.5(<0.001)$ & $-3.1(<0.001)$ \\
Yoko & $-0.3(0.55)$ & $-0.2(0.69)$ & $-4.8(<0.001)$ & $-3.2(<0.001)$ & $-2.3(<0.001)$ \\
Yambela & $0.9(0.09)$ & $-0.5(0.62)$ & $-4.0(<0.001)$ & $-2.4(<0.001)$ & $-0.9(0.08)$ \\
All sites & $-0.3(0.36)$ & $-0.2(0.52)$ & $-5.0(<0.001)$ & $-3.4(<0.001)$ & $-2.2(<0.001)$ \\
\hline
\end{tabular}

A positive sign of MSD indicates underestimation of height, and a negative sign indicates overestimation. All statistics are provided at site level for Yangambi, Yoko, and Yambela and for the combination of the three sites (all sites)

\section{Discussion}

We presented a height-diameter assessment in a data-poor area in the central Congo Basin and assessed the use of estimated heights for the estimation of stand-level characteristics AGB and Lorey's height. We showed that tree height estimations made at site level, i.e., the random effect approach in the NLME model, produced the lowest and insignificant residuals, although the local model without random effects based on all three sites outperformed regional and pan-tropical models. Both the regional (Banin et al. 2012; Feldpausch et al. 2012) and pan-tropical (Chave et al. 2014) models produced significant overestimations in tree height for our study region, which directly translated into significant overestimations of both AGB and Lorey's height. The finding that sitespecific and local height-diameter models outperformed regional and pan-tropical ones is not surprising, as the site dependency in height-diameter models is well described in a wide range of forestry literature (e.g., Huang et al. 2000; Saunders and Wagner 2008; Trorey 1932). However, remote sensing products for AGB estimations are dependent on these models for their calibration (e.g., Asner and Mascaro 2014; Lei and Siqueira 2014; Saatchi et al. 2011; Schlund et al. 2015; Wang et al. 2016). Our results showed that, specifically for the data-poor central Congo Basin, current regional heightdiameter models need to be refined, as their errors were significantly introduced into AGB and Lorey's height estimations. Their current use for calibration of remote sensing products for our specific study area would result in bias. Furthermore, both the regional and pan-tropical models produced a larger bias for large trees. With large trees often containing the majority of the stand carbon within a few individuals (Bastin et al. 2015; Slik et al. 2013), the bias in height estimations for these large trees could significantly increase the bias for total AGB estimation of these trees, propagating into large forest-level aboveground carbon stock errors. This increases the need for optimization of these models for datapoor areas, with the added notion that monitoring strategies for future data acquisition should also integrate the focus on large trees. Overall, a better understanding of spatial variation of height-diameter relationships and forest structure of the central Congo Basin in general remains a key challenge.

The regional dependency of tree height-diameter allometry is a logical assumption, with environmental characteristics more likely to be similar within a region, including climate, biogeographical, and disturbance history and tree species composition. However, defining and delimiting geographic regions where forest structure is similar is not straightforward and highly depends on the characteristics that are selected, e.g., similar ecosystems, biomes, drainage basins, topography, or soil types. The geographical regions for tropical Africa proposed by Feldpausch et al. (2011) were constrained by availability of data with limited spatial range. For example, topography and the origin of the geologic parent material for

Table 3 Parameterization of the three-parameter exponential model $\left(H=a-b e^{-c D}\right)$ fitted by a nonlinear least-square estimation (NLS; local model) and the partial nonlinear mixed effects (NLME) local model with "site" as random effect ( $\alpha$ and $\beta$; see Eq. 2), with three sites Yangambi, Yoko, and Yambela

\begin{tabular}{llllll}
\hline & & $\mathrm{a}(\mathrm{SE})$ & $\mathrm{b}(\mathrm{SE})$ & $\mathrm{c}$ (SE) & RSE \\
\hline Local model & & $39.964(1.664)$ & $36.852(1.279)$ & $0.023(0.002)$ & 4.979 \\
NLME & Fixed & $39.092(1.899)$ & $35.224(1.994)$ & $0.023(0.002)$ & 4.877 \\
& Random & $\alpha$ & $\beta$ & & 3686 \\
& Yangambi & -2.252 & -2.357 & & \\
& Yoko & 1.279 & 2.890 & & \\
& Yambela & 0.973 & -0.533 & & \\
\hline
\end{tabular}


Fig. 4 Plot-level relative error for AGB estimation at the tree sites Yangambi (blue), Yambela (red), and Yoko (green) by comparing AGB estimation using measured tree heights with AGB estimation using modeled tree heights by Feldpausch et al. (2012) (a); Banin et al. (2012) (b); Chave et al. (2014) (c); and the local NLME model (d)
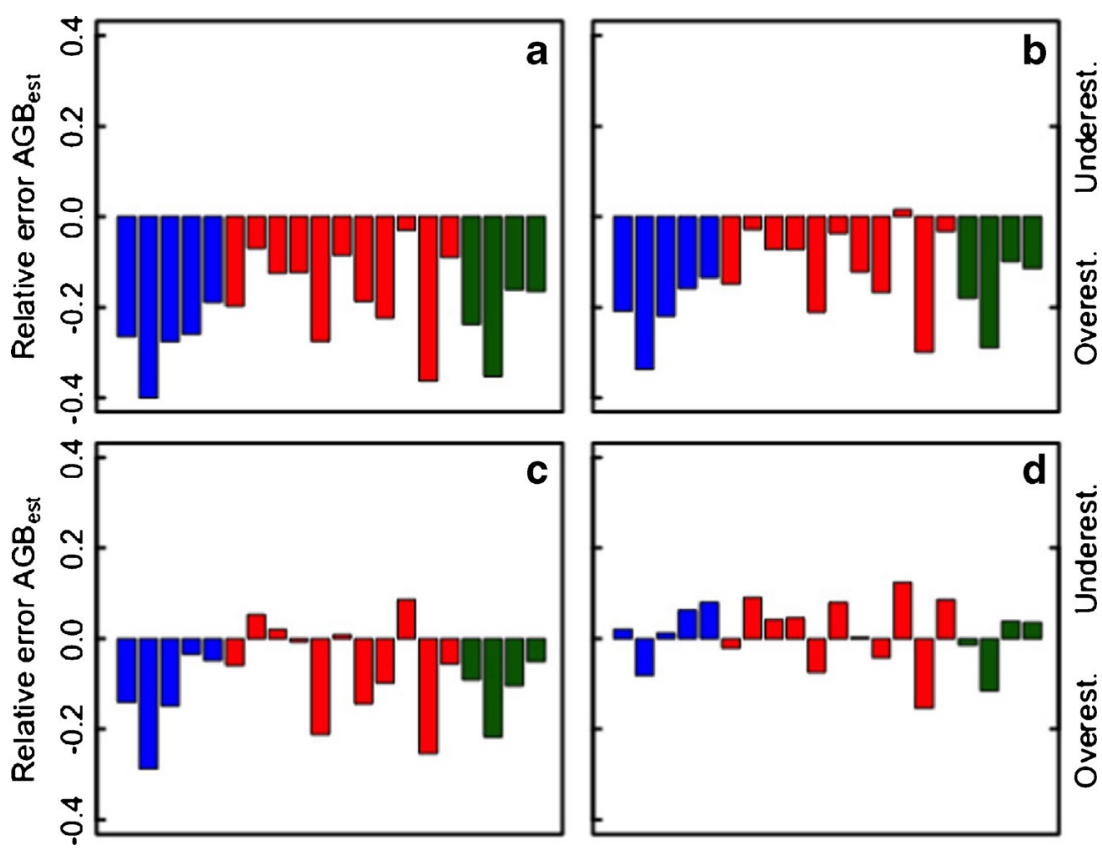

soil development in tropical Africa could not be accounted for, even though various watersheds of the Congo River drainage basin are crossing different geologies (Leturmy et al. 2003). Additionally, the strict hydrographic region of the Congo Basin does not reach Gabon or Cameroon, from which the data were available. Nevertheless, Banin et al. (2012) showed the large-scale intercontinental differences in tree height, even after accounting for environmental conditions, forest structure, and wood density, illustrating that regional depiction of height-diameter allometry is meaningful. However, both regional relationships by Banin et al. (2012) and Feldpausch et al. (2012) produced an overestimation in tree height for our study region. The lower asymptotic tree height found at the three study sites indicates that reduced tree height is possibly more general in this area and that a more localized height-diameter model for the central Congo Basin, instead of central Africa, could possibly reduce the bias. The regional dependency presented by Feldpausch et al. (2011) is thus a good option but needs refinement in particular for data-poor areas.

The pan-tropical model incorporating bioclimatic dependency (Chave et al. 2014) produced lower residuals in height
Fig. 5 Plot-level relative error for Lorey's height estimation at plot level at the tree sites Yangambi (blue), Yambela (red), and Yoko (green) by comparing Lorey's height estimation using measured tree heights with Lorey's height estimation using modeled tree heights by Feldpausch et al. (2012) (a); Banin et al. (2012) (b); Chave et al. (2014) (c); and the local NLME model (d)
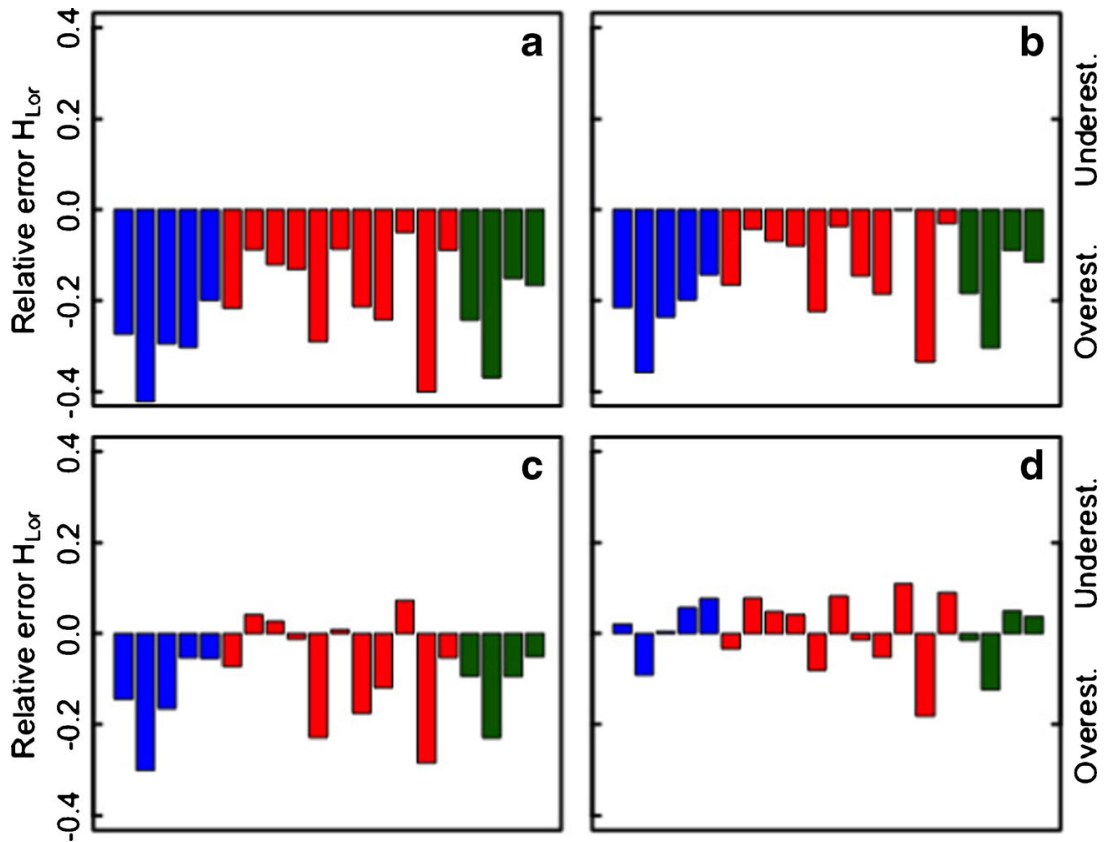
Table 4 Parameter estimates and AIC values for log-transformed scaling $(\log \mathrm{N}=\mathrm{a} \log \mathrm{D}+\mathrm{b})$ and negative exponential $(\log \mathrm{N}=\mathrm{aD}+$ b) functions describing the size-density distributions of the three sites Yangambi, Yoko, and Yambela

\begin{tabular}{llllr}
\hline Sites & Model & $\mathrm{a}(\mathrm{SE})$ & $\mathrm{b}(\mathrm{SE})$ & $\mathrm{AIC}$ \\
\hline Yangambi & $\log \mathrm{N}=\mathrm{alogD}+\mathrm{b}$ & $-2.043(0.116)$ & $4.76(0.18)$ & -27.7 \\
& $\log \mathrm{N}=\mathrm{aD}+\mathrm{b}$ & $-0.026(0.001)$ & $2.64(0.05)$ & -40.4 \\
Yoko & $\log \mathrm{N}=\mathrm{a} \log \mathrm{D}+\mathrm{b}$ & $-2.070(0.072)$ & $4.80(0.12)$ & -55.7 \\
& $\log \mathrm{N}=\mathrm{aD}+\mathrm{b}$ & $-0.022(0.001)$ & $2.50(0.07)$ & -20.9 \\
Yambela & $\log \mathrm{N}=\mathrm{alogD}+\mathrm{b}$ & $-1.499(0.197)$ & $3.26(0.28)$ & -12.3 \\
& $\log \mathrm{N}=\mathrm{aD}+\mathrm{b}$ & $-0.023(0.004)$ & $1.80(0.12)$ & -4.9 \\
\hline
\end{tabular}

$\mathrm{N}$ is the stem density in a diameter bin with diameter midpoint $\mathrm{D}$ estimates for the study area compared to the regional models. Our study thus validates the pan-tropical nature of the presented model and the finding that the bioclimatic stress variable depicting drought tolerance and tolerance to temperature variability improves tree height estimations.

An aspect not accounted for in current height-diameter models for Africa is human activity. Specifically for tropical Africa, the Food and Agriculture Organization of the United Nations (2010) reports high numbers for forested areas classified as "other naturally regenerated forest" (i.e., forest predominantly composed of trees established through natural regeneration, where there are clearly visible indications of human activity) going up to $80 \%$ for western and central Africa, compared to $\sim 20 \%$ for South America. For our study area,
Fig. 6 Stem density distributions (SDD) for Yangambi (a, b), Yoko $(\mathbf{c}, \mathbf{d})$, and Yambela $(\mathbf{e}, \mathbf{f})$. The SDD are plotted on log-log axes (a, c, e), on which relationships described as scaling functions would be linear, and on log-linear axes $(\mathbf{b}, \mathbf{d}, \mathbf{f})$ on which relationships described as negative exponential functions would be linear. Diameter bins with stem densities of less than five individuals are shown as open circles and were excluded from the regression analyses. Model fits as described in Table 4 are shown
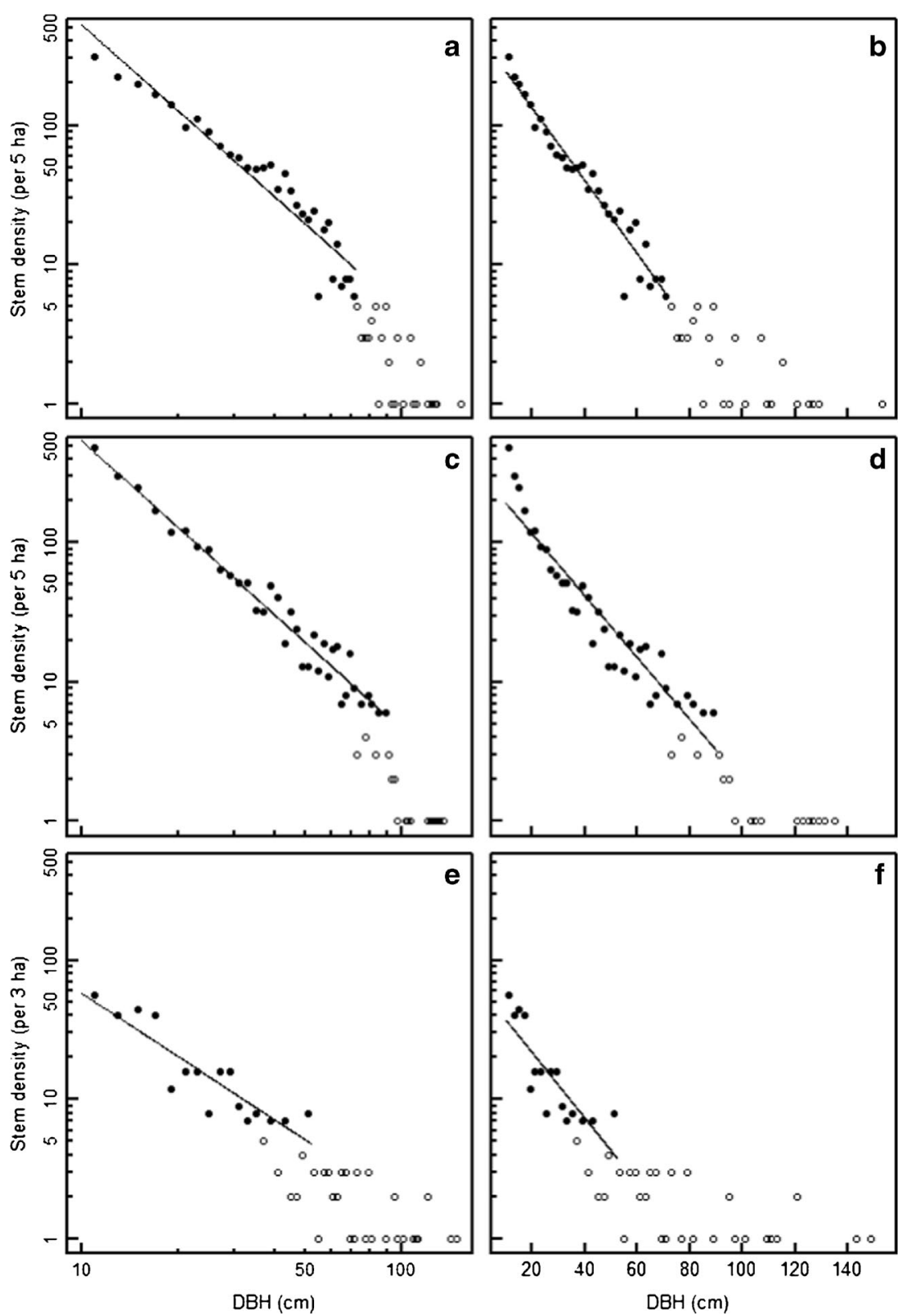
accessibility to the forest could have played an important part in disturbance probabilities, with all sites relatively close to the Congo River, increasing forest accessibility and possible human intervention. The stage of development a forest is in after some form of disturbance will reflect in differences in forest structure and composition (Kerkhoff and Enquist 2007) and can influence height-diameter relationships (Sumida et al. 2013). Specifically, the theoretical asymptote of tree height in a height-diameter relationship increases with stand age (Kohyama et al. 1990; Sumida et al. 2013). Accordingly, our study area, even though the sites are located in forest reserves, could be in a phase of stand development after unrecorded human activities or disturbances, possibly explaining the lower tree heights found. The SDD of Yangambi with the negative exponential function as the best fit could namely suggest past exogenous disturbances (Coomes et al. 2003). Including measures of stand development and disturbance in heightdiameter relationships for tropical Africa could be an important aspect. In general, spatial information on deforestation, reforestation, degradation, and regeneration, as developed by Ernst et al. (2013) for the Congo Basin, could help define regions with altered forest structure, which could be specifically important for naturally regenerated forests in tropical Africa (Food and Agriculture Organization of the United Nations 2010).

Within our local study area, site-specific dependencies still explained a significant part of the variation, as the local model increased in accuracy by introducing site as a random effect. In this study, we were not able to pinpoint the main drivers for the differences in site-level height-diameter relationships, but we list here a few candidate drivers. A first important driver could be differences in soil characteristics. Doetterl et al. (2015) have shown for the Yangambi and Yoko sites that a difference in nutrient limitation, specifically potassium, in part drives a tree's carbon allocation to aboveground vs belowground structures. The lower potassium availability in the soil in Yangambi resulted in higher belowground carbon allocation, possibly also explaining the lower tree height at Yangambi compared to Yoko. Secondly, floristic differences were apparent between the three sites, but could not be taken into account. The high species diversity and low number of per-species observations necessitated pooling of species for model development, as is often the case in tropical forest studies (Hunter et al. 2013). However, height-diameter relationships are species dependent (e.g., Bohlman and O'Brien 2006; Poorter et al. 2003), and neglecting the inter-species differences adds uncertainty. Thirdly, forest structure, commonly accepted to highly influence individual tree height-diameter allometry (Molto et al. 2014; Saunders and Wagner 2008), did not drive local differences between our study sites. Namely, standard forest structure measures stem density, basal area, mean stem diameter, and maximal stem diameter did not differ across the sites. The SDD distributions at the three sites did reveal differences between Yangambi and Yoko. Possible differences in human intervention or developmental stages could explain site-specific differences in height-diameter relationships, although further research is needed. Nevertheless, due to the differences in inventory protocols, we were not able to assess forest structural and floristic differences in great detail and cannot draw specific conclusions. Furthermore, these differences in protocol could be a fourth driver for site-specific variability. Different height observers could have led to systematic differences (e.g., Bohlman and O'Brien 2006), although precautions were taken to minimize these differences by using the same protocol to measure heights of trees that were selected. Moreover, the tree height measurement itself is prone to measurement errors (Larjavaara and Muller-Landau 2013) introducing additional variability into these models. However, differences in measurement protocols will inherently be part of large-scale studies which often depend on data availability of smaller studies and multiple measurement teams. Accounting for this type of variation therefore remains a challenge.

As the site effect improves upon the local height-diameter model, with drivers not incorporated in the regional (spatially driven) and pan-tropical (climate driven) models, this sitelevel variability is currently not captured or accounted for. When using these models for AGB estimation, especially for use in carbon-accounting programs, this variability should be accounted for in error propagation. Alternatively, site-specific parameterization of height-diameter would overcome this bias. This is however not beneficial in terms of fieldwork efforts, since height measurements are both time and cost intensive and not always feasible. As mentioned before, and also put forward by Bastin et al. (2015), a focus on large trees and careful measurement thereof could limit additional field effort during inventory work.

\section{Conclusion}

Spatial variability in height-diameter relationships in central Africa was significant, and general models should be used with caution, especially in data-poor areas. Specifically, at our study area, overestimations made in height estimates produced significant overestimations in both AGB and Lorey's height, both of importance for calibrating remote sensing products. The importance of site-level drivers of variability in tree allometry was also apparent, although additional research of these drivers is needed. Incorporation of site-level variability in the error propagation of more general models could improve their accuracy.

Acknowledgements The fieldwork was possible due to logistic support from UNIKIS, WWF, and Institut National pour l'Etude et la Recherche Agronomiques Yangambi. We thank three anonymous reviewers and 
Jerome Chave for the constructive comments on the previous version of this manuscript.

Funding This research is part of the COBIMFO project (Congo Basin integrated monitoring for forest carbon mitigation and biodiversity; contract no. SD/AR/01A), funded by the Belgian Science Policy Office (Belspo), and the DEFI project (ZRDC2012MP075), funded by the Flemish Interuniversity Council-University Development Cooperation (VLIR-UOS).

\section{References}

Aiba SI, Kitayama K (1999) Structure, composition and species diversity in an altitude-substrate matrix of rain forest tree communities on Mount Kinabalu. Borneo Plant Ecol 140:139-157. doi:10.1023 /A:1009710618040

Asner GP, Mascaro J (2014) Mapping tropical forest carbon: calibrating plot estimates to a simple LiDAR metric. Remote Sens Environ 140: 614-624. doi:10.1016/j.rse.2013.09.023

Banin L, Feldpausch TR, Phillips OL, Baker TR, Lloyd J, Affum-Baffoe K, Arets EJMM, Berry NJ, Bradford M, Brienen RJW, Davies S, Drescher M, Higuchi N, Hilbert DW, Hladik A, Iida Y, Abu Salim K, Kassim AR, King DA, Lopez-Gonzalez G, Metcalfe D, Nilus R, Peh KSH, Reitsma JM, Sonké B, Taedoumg H, Tan S, White L, Wöll H, Lewis SL (2012) What controls tropical forest architecture? Testing environmental, structural and floristic drivers. Glob Ecol Biogeogr 21:1179-1190. doi:10.1111/j.1466-8238.2012.00778.x

Bastin JF, Barbier N, Réjou-Méchain M, Fayolle A, Gourlet-Fleury S, Maniatis D, de Haulleville T, Baya F, Beeckman H, Beina D, Couteron P, Chuyong G, Dauby G, Doucet JL, Droissart V, Dufrêne M, Ewango C, Gillet JF, Gonmadje CH, Hart T, Kavali T, Kenfack D, Libalah M, Malhi Y, Makana JR, Pélissier R, Ploton P, Serckx A, Sonké B, Stevart T, Thomas DW, De Cannière C, Bogaert J (2015) Seeing central African forests through their largest trees. Sci Rep 5:13156. doi:10.1038/srep13156

Bohlman S, O'Brien S (2006) Allometry, adult stature and regeneration requirement of 65 tree species on Barro Colorado Island, Panama. J Trop Ecol 222:123-136. doi:10.1017/S0266467405003019

Burnham KP, Anderson DR (2002) Model selection and inference: a practical information-theoretic approach, 2nd edn. Springer, New York

Chave J, Réjou-Méchain M, Búrquez A, Chidumayo E, Colgan MS, Delitti WBC, Duque A, Eid T, Fearnside PM, Goodman RC, Henry M, Martínez-Yrízar A, Mugasha WA, Muller-Landau HC, Mencuccini M, Nelson BW, Ngomanda A, Nogueira EM, OrtizMalavassi E, Pélissier R, Ploton P, Ryan CM, Saldarriaga JG, Vieilledent $G$ (2014) Improved allometric models to estimate the aboveground biomass of tropical trees. Glob Change Biol 20: 3177-3190. doi:10.1111/gcb.12629

Chave J, Coomes DA, Jansen S, Lewis SL, Swenson NG, Zanne AE (2009) Towards a worldwide wood economics spectrum. Ecol Lett 12:351-366. doi:10.1111/j.1461-0248.2009.01285.x

Coomes DA, Duncan RP, Allen RB, Truscott J (2003) Disturbances prevent stem size-density distributions in natural forests from following scaling relationships. Ecol Lett 6:980-989. doi:10.1046/j.14610248.2003.00520.x

Curtis RO (1967) Height-diameter and height-diameter-age equations for second-growth Douglas-fir. For Sci 13:365-375

Doetterl S, Kearsley E, Bauters M, Hufkens K, Lisingo J, Baert G, Verbeeck H, Boeckx P (2015) Aboveground vs. belowground carbon stocks in African tropical lowland rainforest: drivers and implications. PLoS One 10:e0143209. doi:10.1371/journal. pone. 0143209
Ernst C, Mayaux P, Verhegghen A, Bodart C, Christophe M, Defourny P (2013) National forest cover change in Congo Basin: deforestation, reforestation, degradation and regeneration for the years 1990, 2000 and 2005. Glob Change Biol 19:1173-1187. doi:10.1111/gcb.12092

Feldpausch TR, Banin L, Phillips OL, Baker TR, Lewis SL, Quesada CA, Affum-Baffoe K, Arets EJMM, Berry NJ, Bird M, Brondizio ES, de Camargo P, Chave J, Djagbletey G, Domingues TF, Drescher M, Fearnside PM, França MB, Fyllas NM, Lopez-Gonzalez G, Hladik A, Higuchi N, Hunter MO, Iida Y, Salim KA, Kassim AR, Keller M, Kemp J, King DA, Lovett JC, Marimon BS, Marimon-Junior BH, Lenza E, Marshall AR, Metcalfe DJ, Mitchard ETA, Moran EF, Nelson BW, Nilus R, Nogueira EM, Palace M, Patiño S, Peh KSH, Raventos MT, Reitsma JM, Saiz G, Schrodt F, Sonké B, Taedoumg HE, Tan S, White L, Wöll H, Lloyd J (2011) Heightdiameter allometry of tropical forest trees. Biogeosciences 8:10811106. doi:10.5194/bg-8-1081-2011

Feldpausch TR, Lloyd J, Lewis SL, Brienen RJW, Gloor M, Monteagudo Mendoza A, Lopez-Gonzalez G, Banin L, Abu Salim K, AffumBaffoe K, Alexiades M, Almeida S, Amaral I, Andrade A, Aragão LEOC, Araujo Murakami A, Arets EJMM, Arroyo L, Aymard CGA, Baker TR, Bánki OS, Berry NJ, Cardozo N, Chave J, Comiskey JA, Alvarez E, de Oliveira A, Di Fiore A, Djagbletey G, Domingues TF, Erwin TL, Fearnside PM, França MB, Freitas MA, Higuchi N, Iida Y, Jiménez E, Kassim AR, Killeen TJ, Laurance WF, Lovett JC, Malhi Y, Marimon BS, Marimon-Junior BH, Lenza E, Marshall AR, Mendoza C, Metcalfe DJ, Mitchard ETA, Neill DA, Nelson BW, Nilus R, Nogueira EM, Parada A, Peh KSH, Pena Cruz A, Peñuela MC, Pitman NCA, Prieto A, Quesada CA, Ramírez F, Ramírez-Angulo H, Reitsma JM, Rudas A, Saiz G, Salomão RP, Schwarz M, Silva N, Silva-Espejo JE, Silveira M, Sonké B, Stropp J, Taedoumg HE, Tan S, ter Steege $\mathrm{H}$, Terborgh J, Torello-Raventos M, van der Heijden GMF, Vásquez R, Vilanova E, Vos VA, White L, Willcock S, Woell H, Phillips OL (2012) Tree height integrated into pantropical forest biomass estimates. Biogeosciences 9:3381-3403. doi:10.5194/bg9-3381-2012

Food and Agriculture Organization of the United Nations (2010) Global Forest Resources Assessment. FAO Forestry Paper 163

Gilson P, Van Wambeke A, Gutzweiler R (1956) Notice explicative de la carte des sols et de la végétation, $\mathrm{N}^{\circ}$ 6: Yangambi, planchette 2: Yangambi. INEAC, Bruxelles

Heineman KD, Jensen E, Shapland A, Bogenrief B, Tan S, Rebarber R, Russo SE (2011) The effects of belowground resources on aboveground allometric growth in Bornean tree species. Forest Ecol Manag 261:1820-1832. doi:10.1016/j.foreco.2011.02.005

Henry HAL, Aarssen LW (1999) The interpretation of stem diameterheight allometry in trees: biomechanical constraints, neighbour effects, or biased regressions? Ecol Lett 2:89-97. doi:10.1046/j.14610248.1999.22054.x

Hill MO, Gauch HG (1980) Detrended correspondence analysis: an improved ordination technique. Vegetatio 42:47-58. doi:10.1007 /BF00048870

Holbrook NM, Putz FE (1989) Influence of neighbors on tree form: effects of lateral shade and prevention of sway on the allometry of Liquidambar styraciflua (sweet gum). Am J Bot 76:1740-1749. doi: $10.2307 / 2444473$

Huang S, Price D, Titus SJ (2000) Development of ecoregion-based height-diameter models for white spruce in boreal forests. Forest Ecol Manag 129:125-141. doi:10.1016/S0378-1127(99)00151-6

Hulshof CM, Swenson NG, Weiser MD (2015) Tree height-diameter allometry across the United States. Ecol Evol 5:1193-1204. doi: $10.1002 /$ ece 3.1328

Hunter MO, Keller M, Victoria D, Morton DC (2013) Tree height and tropical forest biomass estimation. Biogeosciences 10:8385-8399. doi:10.5194/bg-10-8385-2013 
Kearsley E, de Haulleville T, Hufkens K, Kidimbu A, Toirambe B, Baert G, Huygens D, Kebede Y, Defourny P, Bogaert J, Beeckman H, Steppe K, Boeckx P, Verbeeck H (2013) Conventional tree heightdiameter relationships significantly overestimate aboveground carbon stocks in the Central Congo Basin. Nat Comm 4:2269. doi:10.1038/ncomms 3269

Kerkhoff AJ, Enquist BJ (2007) The implications of scaling approaches for understanding resilience and reorganization in ecosystems. Bioscience 57:489-499. doi:10.1641/B570606

Kohyama T, Hara T, Tadaki Y (1990) Patterns of trunk diameter, tree height and crown depth in crowded Abies stands. Ann BotLondon 65:567-574

Larjavaara M, Muller-Landau HC (2013) Measuring tree height: a quantitative comparison of two common field methods in a moist tropical forest. Methods Ecol Evol 4:793-801. doi:10.1111/2041-210 X.12071

Lei Y, Siqueira P (2014) Estimation of forest height using spaceborne repeat-pass L-band InSAR correlation magnitude over the US state of Maine. Rem. Sens. 6:10252-10285. doi:10.3390/rs61110252

Leturmy P, Lucazeau F, Brigaud F (2003) Dynamic interactions between the gulf of Guinea passive margin and the Congo River drainage basin: 1. Morphology and mass balance. J Geophys Res 108:2383. doi:10.1029/2002JB001927

Lewis SL, Sonké B, Sunderland T, Begne SK, Lopez-Gonzalez G, van der Heijden GMF, Phillips OL, Affum-Baffoe K, Baker TR, Banin L, Bastin JF, Beeckman H, Boeckx P, Bogaert J, De Cannière C, Chezeaux E, Clark CJ, Collins M, Djagbletey G, Djuikouo MNK, Droissart V, Doucet JL, Ewango CEN, Fauset S, Feldpausch TR, Foli EG, Gillet JF, Hamilton AC, Harris DJ, Hart TB, de Haulleville T, Hladik A, Hufkens K, Huygens D, Jeanmart P, Jeffery KJ, Kearsley E, Leal ME, Lloyd J, Lovett JC, Makana JR, Malhi Y, Marshall AR, Ojo L, Peh KSH, Pickavance G, Poulsen JR, Reitsma JM, Sheil D, Simo M, Steppe K, Taedoumg HE, Talbot J, Taplin JRD, Taylor D, Thomas SC, Toirambe B, Verbeeck H, Vleminckx J, White LJT, Willcock S, Woell H, Zemagho L (2013) Above-ground biomass and structure of 260 African tropical forests. Philos T Roy Soc B, Biol Sci 368:20120295. doi:10.1098 /rstb.2012.0295

Lines ER, Zavala MA, Purves DW, Coomes DA (2012) Predictable changes in aboveground allometry of trees along gradients of temperature, aridity and competition. Glob Ecol Biogeogr 21:10171028. doi:10.1111/j.1466-8238.2011.00746.x

Molto Q, Hérault B, Boreux JJ, Daullet M, Rousteau A, Rossi V (2014) Predicting tree heights for biomass estimates in tropical forests-a test from French Guiana. Biogeosciences 11:3121-3130. doi:10.5194/bg-11-3121-2014

Oksanen J (2013) Multivariate analyses of ecological communities in R: vegan tutorial

Phillips OL, Baker TR, Brienen R, Feldpausch TR (2010) Field manual for plot establishment and remeasurement, available at http://www. geog.leeds.ac.uk/projects/rainfor/ (last Access: Nov 2012)

Pinheiro JC, Bates DM, Debroy S, Sarkar D (2009) Nlme: linear and nonlinear mixed effects models. $\mathrm{R}$ package version 3:1-93

Pinheiro JC, Bates DM (2000) Mixed-effects models in S and S-PLUS, 1 st edn. Springer Verlag, New York

Poorter L, Bongers F, Sterck FJ, Wöll H (2003) Architecture of 53 rain forest tree species differing in adult stature and shade tolerance. Ecology 84:602-608
Popkin G (2015) Weighing the world's trees. Nature 523:20-22. doi:10.1038/523020a

Ryan M, Yoder B (1997) Hydraulic limits to tree height and tree growth. Bioscience 47:235-242. doi:10.2307/1313077

Saatchi S, Marlier M, Chazdon RL, Clark DB, Russell AE (2011) Impact of spatial variability of tropical forest structure on radar estimation of aboveground biomass. Remote Sens Environ 115:2836-2849. doi:10.1016/j.rse.2010.07.015

Saunders MR, Wagner RG (2008) Height-diameter models with random coefficients and site variables for tree species of Central Maine. Ann For Sci 65:203. doi:10.1051/forest:2007086

Schlund M, von Poncet F, Kuntz S, Schmullius C, Hoekman DH (2015) TanDEM-X data for aboveground biomass retrieval in a tropical peat swamp Forest. Remote Sens Environ 158:255-266. doi:10.1016/j.rse.2014.11.016

Slik FJW, Paoli G, McGuire K, Amaral I, Barroso J, Bastian M, Blanc L, Bongers F, Boundja P, Clark C, Collins M, Dauby G, Ding Y, Doucet JL, Eler E, Ferreira L, Forshed O, Fredriksson G, Gillet JF, Harris D, Leal M, Laumonier Y, Malhi Y, Mansor A, Martin E, Miyamoto K, Araujo-Murakami A, Nagamasu H, Nilus R, Nurtjahya E, Oliveira E, Onrizal O, Parada-Gutierrez A, Permana A, Poorter L, Poulsen J, Ramirez-Angulo H, Reitsma J, Rovero F, Rozak A, Sheil D, Silva-Espejo J, Silveira M, Spironelo W, ter Steege H, Stevart T, Navarro-Aguilar GE, Sunderland T, Suzuki E, Tang J, Theilade I, van der Heijden G, van Valkenburg J, Van Do T, Vilanova E, Vos V, Wich S, Wöll H, Yoneda T, Zang R, Zhang MG, Zweifel N (2013) Large trees drive forest aboveground biomass variation in moist lowland forests across the tropics. Glob Ecol Biogeogr 12:1261-1271. doi:10.1111/geb.12092

Sterck FJ, Bongers F (1998) Ontogenetic changes in size, allometry, and mechanical design of tropical rain forest trees. Am J Bot 85:266272. doi: $10.2307 / 2446315$

Stout BB, Shumway DL (1982) Site quality estimation using height and diameter. For Sci 28:639-645

Sumida A, Miyaura T, Torii H (2013) Relationships of tree height and diameter at breast height revisited: analyses of stem growth using 20-year data of an even-aged Chamaecyparis obtusa stand. Tree Physiol 33:106-118. doi:10.1093/treephys/tps127

Trorey LG (1932) A mathematical method for the construction of diameter height curves based on site. Forest Chron 8:121-132. doi: $10.5558 / \mathrm{tfc} 8121-2$

Urban J, Holušová K, Menšík L, Čermák J, Kantor P (2013) Tree allometry of Douglas fir and Norway spruce on a nutrient-poor and a nutrient-rich site. Trees Struct Funct 27:97-110. doi:10.1007 /s00468-012-0771-y

Van Engelen VWP, Verdoodt A, Dijkshoorn JA, Ranst EV (2006) Soil and terrain database of Central Africa (DR Congo, Burundi, Rwanda). Ghent University, FAO \& ISRIC, Wageningen

Verbeeck H, Boeckx P, Steppe K (2011) Tropical forests: include Congo Basin. Nature 479:179

Wang C, Wang L, Fu H, Xie Q, Zhu J (2016) The impact of forest density on forest height inversion modeling from polarimetric InSAR data. Rem Sens 8:291. doi:10.3390/rs8040291

Wang X, Fang J, Tang Z, Zhu B (2006) Climatic control of primary forest structure and DBH-height allometry in northeast China. Forest Ecol Manag 234:264-274. doi:10.1016/j.foreco.2006.07.007

World reference base (WRB) for soil resources (2014) International soil classification system for naming soils and creating legends for soil maps. World Soil Resources Report 106. Rome, Italy 